\title{
|قتصاديات إنتاج محصول القطن في محافظة البحيرة
}

\author{
طارق مرسى مسعود، شيرين محمد عفت الفار، أثرف السيد مصطفى

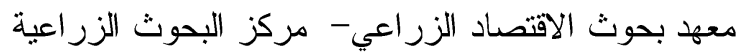 \\ الملخص
}

استهذف البحث دراسة اقتصاديات إنتاج محصول القطن في الزراعة المصرية وفي محافظة البحيرة ونقدير أهم المؤشرات الإنتاجية،

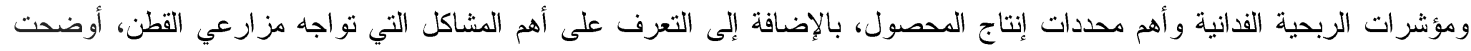

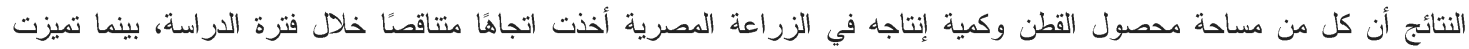
الإنتاجية الفذانية بالثبات النسبي خلال نفس الفتزة. كما تبين ارتفاع قيمة معامل الاختلاف المقدر لكل من السعر المزرعي، وتكاليف الإنتاج، وصافي العائد للفدان خلال فتزة الدراسة وهو ما يعد مؤشر على ارتفاع درجة المخاطرة التي تو اجه مز ارعي القطن في مصنر.

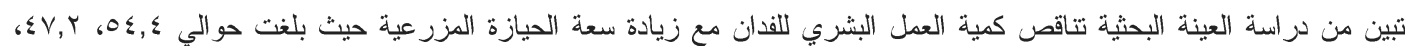

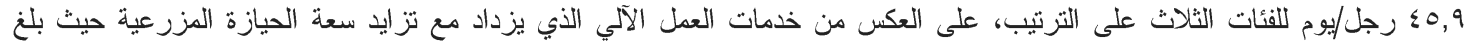

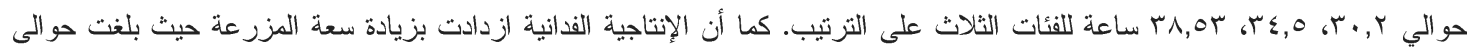

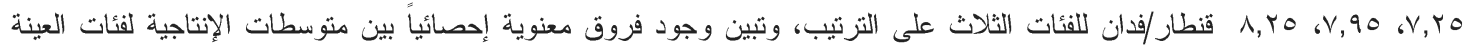

البحثية.

و اتضح من دالات الإنتاج المقدرة أن أهم محددات إنتاج القطن كل من العمل البشري والعمل الآلي والمبيدات الزراعية، وأن المزارع بفئات العينة الثلاث لا تحقق الكفاءة في استخدام الموارد بل أن هناك إسر اف في استخدام بعضها كالعمل البشري في الفئة الأولى إلى الحد

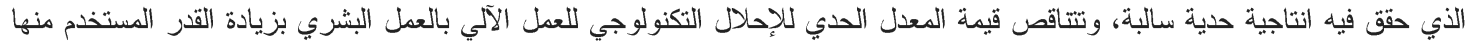
في العملية الإنتاجية وهو ما يتفق مع المنطق الاقتصادي. تمثلت أهم المشاكل التي تو اجه مزارعي القطن بالعينة البحثية بمحافظة البحيرة في مشكلة ارتفاع أجور العمالة الزراعية، وعدم توفر العمالة بالقدر الكافي في موسم الحصاد، وعدم تحديد سعر ضمان للمحصول قبل الزراعة بوقت كافي، ومشكلة صعوبة تسويق الإنتاج في

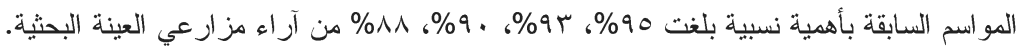

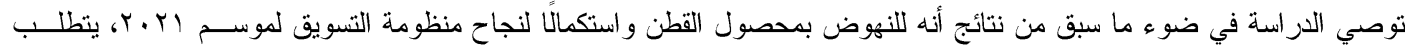

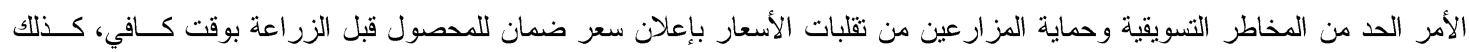

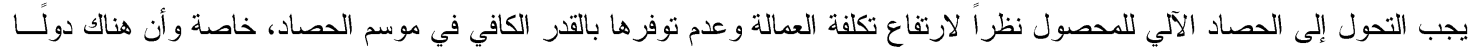

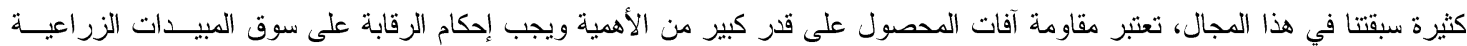
والدذ من عملية الغش، كذلك توفير الأسمدة الزراعية بالجمعيات الزراعية بالقدر الكافي وفي الوقت المناسب.

الكلمات المفتاحية: البحيرة، القطن، انتاج، اقتصاد، قياس.

إنتاج زيت الطعام من عصر بذور القطن، وتوفير كمية كبيرة من الأعلاف الحيو انية المركزة منمنلة في الكسب ونب ونون الناتج من عصر البذور.

توسعت زر اعة القطن فى بداية فترة السبعينات من من

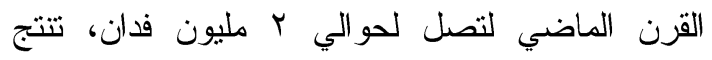
حوالي سا مليون قنطار من القطن ينم تصدير قرابة النصف و الباقي يصنع محلياً (الثاطر، 9 9. . r). بدأ التدهور لمحصول القطن مع تطبيق سياسات الانفتاح

\section{المقدمة}

يعتبر القطن من أهم المحاصيل الاستراتيجية في

الزراعة المصرية سواء للمزارع كمحصول يحقق له عائد مناسب، أو للدولة لأهميته التصديرية لما يتمتع به لهاء القطن المصري من مواصفات تجعله من أجود الأقطان

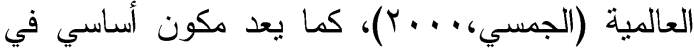
صناعات الغزل و النسيج و الملابس الجاهزة، إلى جانب 
تعد محافظة البحيرة من أكبر المحافظات الزراعية في مصر ، ويشكل محصول القطن بالمحافظة مكون

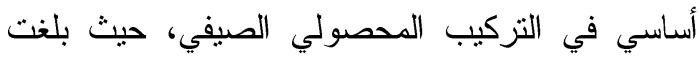
مساحته في المحافظة حو الي TV,T ألف فدان تمثل نحو في \% 10,V

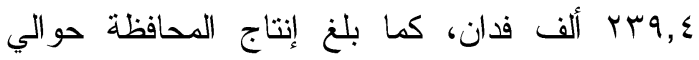
roo,V إنتاج القطن في مصر البالغ حوالي ^, إ مليون قنطار

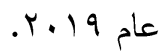

\section{المشكلة البحثية}

بالرغم من الأهمية الاقتصادية لمحصول القطن إلا

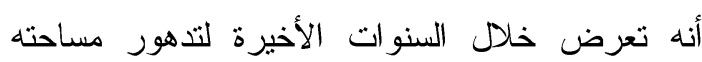
وجودته، مما أدى إلى تضاؤل مكانته في التركيب المحصولي، و انخفاض صادراته إلى الأسواق الدولية.

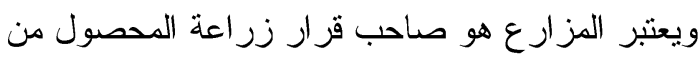
عدمه، وفي ظل ما يواجه من ارتفاع تكاليف زر اعة هون

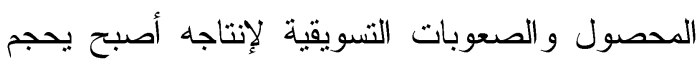
عن زر اعته، الأمر الذي يتطلب دراسة الواقع الإنتاجي

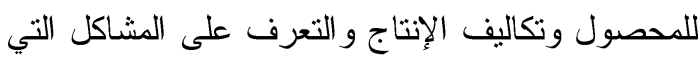
تواجه مزارعي القطن بمحافظة البحيرة بوصفها من أهم المحافظات المنتجة للمحصول.

\section{الأهداف البحثية}

بستهدف البحث دراسة اقتصاديات إنتاج محـصول القطن في الزر اعة المصرية بصفة عامـــة ومحافظــــة

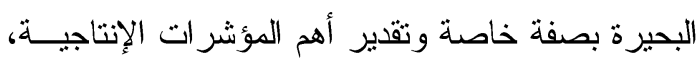

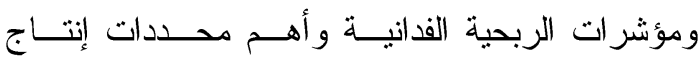

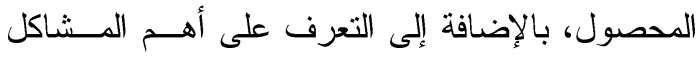

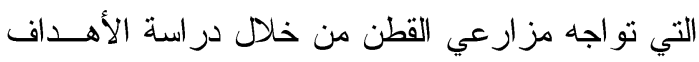

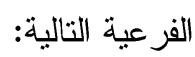

أو لاً: المؤشر اته الإنتاجية والاقتصادية لمحصول القطن

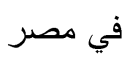

ثانياً: المؤشرات الإنتاجية والاقتصادية لمحصول القطن

$$
\text { بعينة الدر اسة في محافظة البحيرة }
$$

وفتح أبواب الاستير اد للمنسوجات من العالم الخارجي، مع عجز صناعة الغزل والنسيج عن التقدم خلال فترة الثمانينات و التسعينات بسبب تقادم الآلات ووسائل الإنتاج، فضلًا عن تحرير تجارة القطن في عام \199 199 جعل المزارع عرضة للتأثز بالأسعار العالمية وتقلباتها

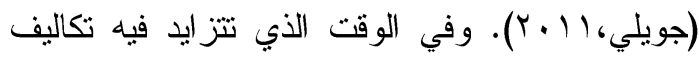

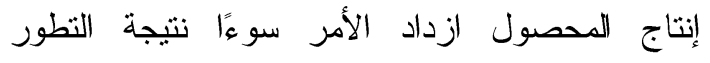
التكنولوجي في مصانع الغزل و النسيج وأصبح الاعتماد

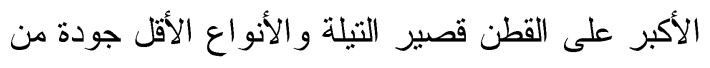
القطن المصري، وكذلك دخول الألياف الصناعية في صناعة المنسوجات أدى إلى ضعف الطلب الخارجي و الداخلي على القطن المصري طويل الثيلة مرتفع

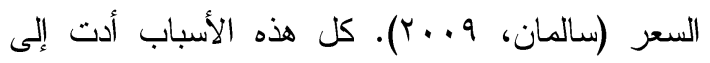

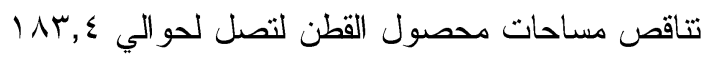

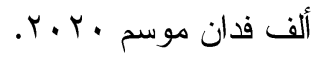
تهدف سياسة الدولة في الآونة الأخيرة إلى استعادة القطن المصري مكانته سواء في الأسواق الدولية أو السوق المحلي، باتخاذ بعض الاجر اءات مثل إنشاء أكبر

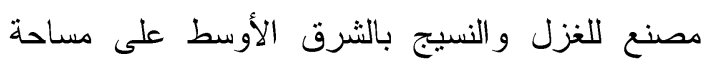
ك, Y ألف متر مربع بمدينة المحلة بطاقة إنتاجية

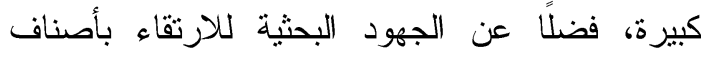

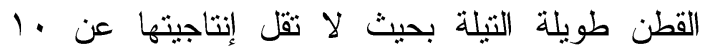

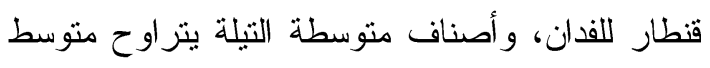

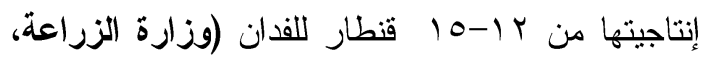

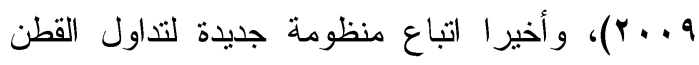

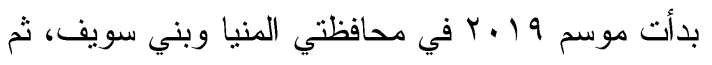
عمثت على كل المحافظات، وهي تعتمد على حصر

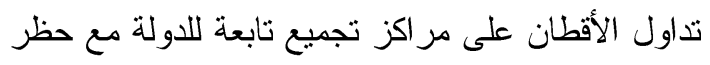

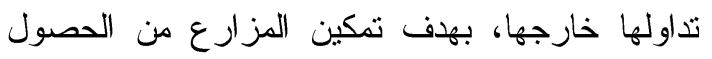
على أعلى سعر من خلال عرض إنتاجه في مزادات علنية تحت إثراف الهيئة العامة للتحكيم واختبار ات ات القطن، على أن يفتتح المز اد بمتوسط سعر الأسعار

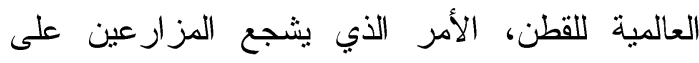
التوسع في زر اعة القطن خلال المو اسم المقبلة. 
المزارعين، تم اختيار مركزي أبو حمص وكفر الدوار

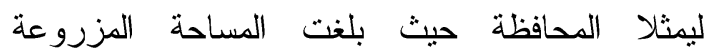

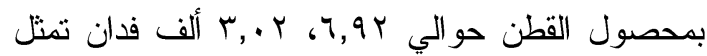

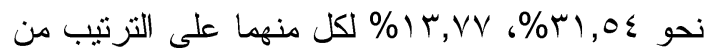
مساحة القطن في محافظة البحيرة و التي بلغت حوالي

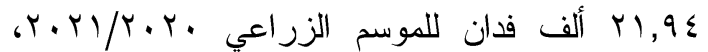

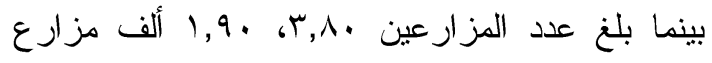

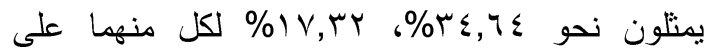
الترتيب من عدد المزارعين في المحافظة. جدول (1). كما تم اختبار ثلاث قرى من كل مركز وفقاً للأهمية النسبية وهم طلمبات برسيق و العشرة و أبو هواش من من مركز أبوحمص وقري الوسطانبة و الطرح ومنشأة بلبع من مركز كفر الدوار، وتم تحديد حجم العينة بحوالي • r r مشاهدة من مزارعي القطن بالقرى المختارة تم

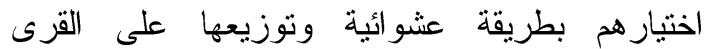
المختارة كما هو موضح بالجدول (Y). وقد تم تقسيم العينة البحثية إلى ثلاث فئات حبازة، الفئة الأولى تضم

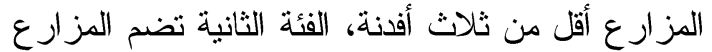
من ثلاث أفدنة لأفل من خمسة أفدنة و الفئة الثالثة تضم المزارع خمسة أفدنة فأكثر، وبلغ حجم العينة البحثية

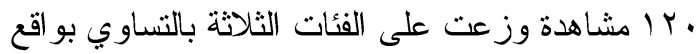
• كشاهدة لكل فئة، وبلغ متوسط حجم المزرعة لفئات

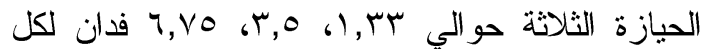

$$
\text { منهم على الترتيب. }
$$

ثالثاً: التقدير القياسي لدوال إنتاج محصول القطن بعينة

$$
\text { الدر اسة في محافظة البحيرة }
$$

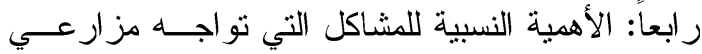
القطن بالعينة البحثية في محافظة البحيرة

$$
\text { الأسلوب البحثي ومصادر البيانات }
$$

اعتمد البحث في تحقيق أهدافه على كل من التحليل الاقتصادي الوصفي والكمي وذلك من خلال اســتخدام

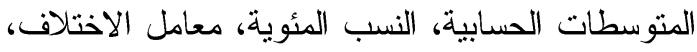
ومؤشرات الربحية الفدانية، وتحليل التباين فـــي اتجـــاه واحد لاختبار الفرق بين متوسطات بعض المؤشــرات

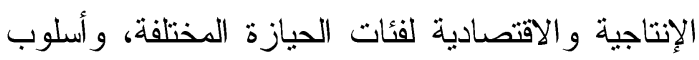

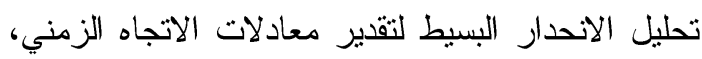

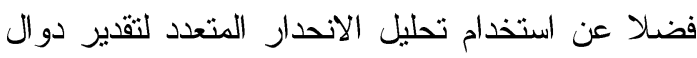
الإنتاج لمحصول القطن في صور ها المختلفة.

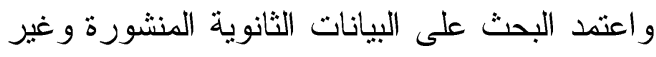
المنشورة المتعلقة بموضوع الدراسة من مصن مصادرها المختلفة بالإضافة إلى البيانات الأولية التي نم الحصول بونه عليها من عينة عثوائية لمزارعي القطن بمحافظة البحيرة وذلك من خلال استمارة استبيان تم تصميمها تهنها لتفي بالغرض من البحث، وتم تجمعها بأسلوب المقابلة الثخصية مع مزارعي العينة المختارة.

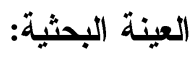
استتاداً للأهمبة النسبية لمر اكز محافظة البحيرة من البهابة حيث المساحة المزروعة بمحصول القطن وأعداد

\begin{tabular}{|c|c|c|c|c|}
\hline \multicolumn{2}{|c|}{ عدد الحائزين } & \multicolumn{2}{|c|}{ المساحة المزروعة } & \multirow{2}{*}{ البيان } \\
\hline$\%$ & ألف حائز & $\%$ & ألف فدان & \\
\hline$r \leqslant, T \leqslant$ & $r, \Lambda$ & $r 1,0 \leqslant$ & 7,94 & مركز أبو حمص \\
\hline IV,rY & 1,9 & $I T, V V$ & $r, \cdot r$ & مركز كفر الدوار \\
\hline 01,97 & $0, \mathrm{~V}$ & $\leq 0, r$ & $9,9 \leq$ & إجمالي المركزين \\
\hline$\leqslant \Lambda, \cdot \leqslant$ & $0, Y V$ & $0 \leqslant, V$ & $I_{1}, \ldots$ & باقي الَّمر اكز \\
\hline $1 \ldots$ & $1 \cdot, 9 \mathrm{~V}$ & $1 \ldots$ & Y),9 & محافظة البحيرة \\
\hline
\end{tabular}

جدول ا: الأهمية النسبية لمراكز عينة الاراسة وفقاً للمساحة المزروعة بمحصول القطن وعدد المزارعين في

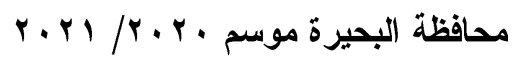


جدول r: توزيع العينة البحثية لمزارعي القطن على القزى المختارة بمركزي أبو حمص ودمنهور موسم $r \cdot r / / r \cdot r$.

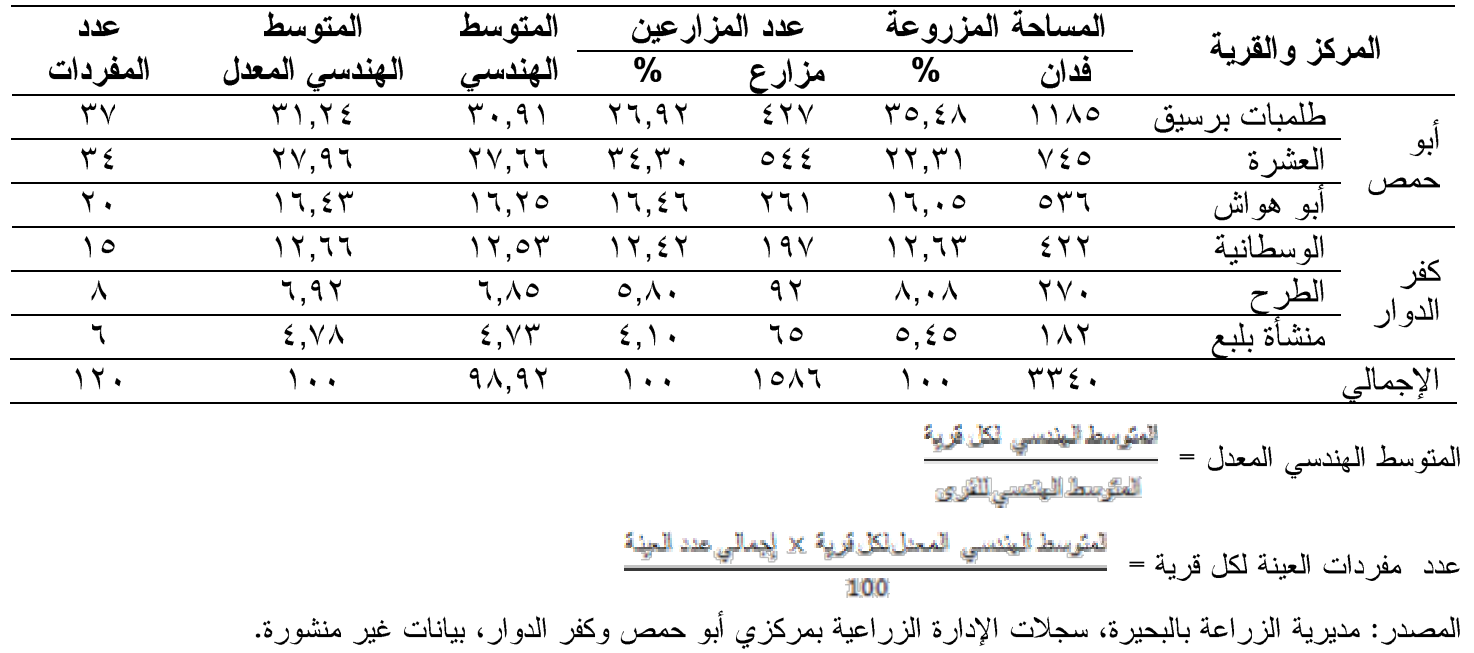

نحو r\%, ب0, من متوسط الفترة، أبي بمقدار تتاقص

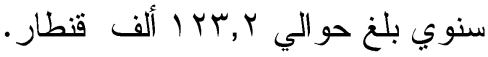

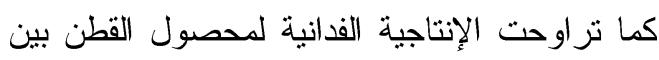

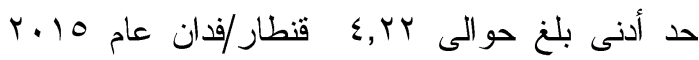

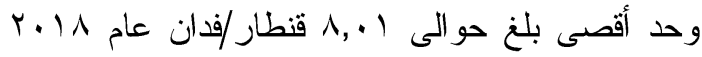
بمتوسط بلغ حوالى 7,0 قنطار/فدان. وبتقدير معادلة

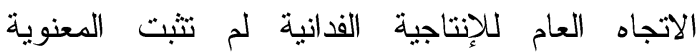

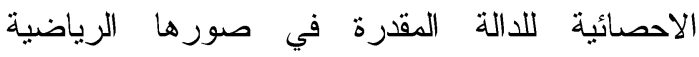
المختلفة، وهو ما يشبر إلى الثبات النسبي لها وهذا ما هالها تؤكده القيمة المنخفضة لمعامل الاختلاف و المقدرة بنحو ؟ إ 10 لفترة الدر اسة. بينما تزاوح السعر المزرعي بين حد أدنى بلغ

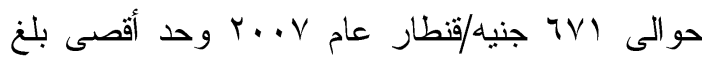

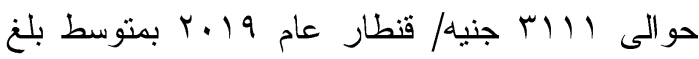

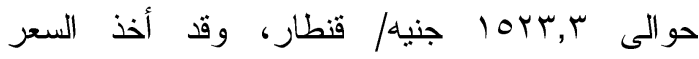
المزرعي اتجاهًا متز ايدًا خلال فترة الدر اسة بمعدل نمو

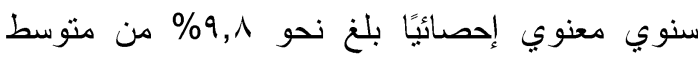

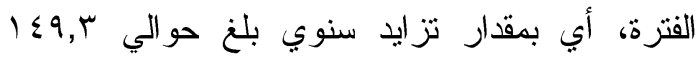

\section{النتائج البحثية ومناقشتها}

أولاً: المؤشرات الإنتاجية والاقتصادية لمحصول القطن

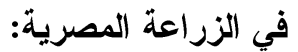

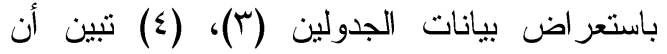

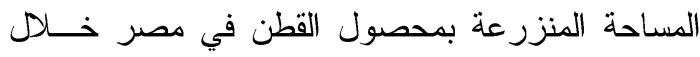

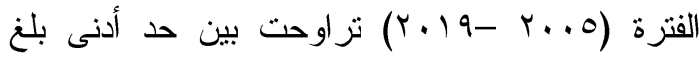

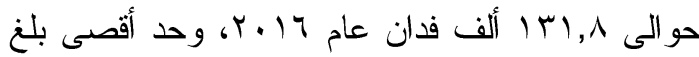

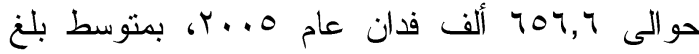
حوالى ,r,1 ألف فدان، وبتقدير معادلة الاتجاه للمساحة المنزرعة خلال فتزة الدراسة تبين أنها تأخذ الخذان اتجاه متتاقص بمعدل تتاقص سنوي معنوي إحصائياً بلغ نحو \%0,0\% من متوسط الفترة، أي بمقدار تتاقص سنوي بلغ حو الي 19,90 ألف فدان. كما تبين أن كمية الإنتاج من محصول لئول القطن نراوح

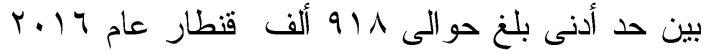

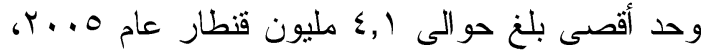
بمنوسط بلغ حوالى ؟ , مليون قنطار ، وبتقدير معادلة الاتجاه لكمية الإنتاج خلال فترة الدراسة تبين أنها تأخذ اتجاه متتاقص بمعدل تتاقص سنوي معنوي إحصائياً بلغ 


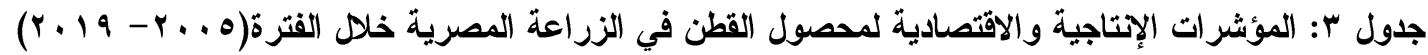

\begin{tabular}{|c|c|c|c|c|c|c|c|}
\hline صنيه/فئان العائد & اجنيالي العائد (1) & تكاليف الفدان & سعز المحصول قنطار & 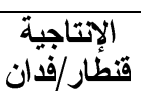 & ألف الإتـاج & ألف فداحة & السنة \\
\hline Y.OA, & $\leqslant 7 \vee 0,1$ & YTIV & VHT & $7, Y Y$ & $\varepsilon \cdot \lambda \varepsilon$, & 707,09 & Y... \\
\hline rษ人9,. & $070 \leqslant,$. & Y970 & $\vee \wedge$. & $v, 1$ & $\Gamma \wedge \cdot \Lambda, \xi$ & OrM, s. & $Y \ldots T$ \\
\hline $1499,$. & EVMY,. & $\mu \leq \mu V$ & $7 \times 1$ & $7, \wedge 7$ & $r q \leq 1,7$ & $O V \leqslant, O V$ & $Y \ldots V$ \\
\hline$M Y Y, A$ & Or $\leqslant V, \Lambda$ & EIT. & 1.7 & $7, \leqslant 7$ & $r \cdot r \cdot, l$ & $M|r, V|$ & $r \ldots \lambda$ \\
\hline $00 \mathrm{r}, \mathrm{V}$ & $\leqslant 001, \mathrm{~V}$ & r991 & $7 \times 9$ & $7, r$ & $1 \vee 91,9$ & $r \wedge \varepsilon, \Sigma \Gamma$ & $r \ldots q$ \\
\hline \&) Y 0,1 & А५ & $\leqslant 0 V 1$ & ITE. & $7, \leqslant 9$ & $r r q 0, V$ & $E \cdot Y, Y \wedge$ & $r \cdot 1$. \\
\hline MY 0,1 & $\wedge \varepsilon \cdot \lambda, \wedge$ & 0194 & 1.77 & $V, V \leqslant$ & $E \cdot Y O, V$ & Or.,Ir & $r .11$ \\
\hline IYKT,V & $T V I T, V$ & $0 \leq 9$. & 1179 & 0,09 & 1АYr,o & צח,ש & $r .1 Y$ \\
\hline YAM., I & $\wedge \leq 07,1$ & OYYY & $1 \leq V \leq$ & 0,71 & $17 \cdot 1,0$ & YAY,VY & $r .1 T$ \\
\hline$\leqslant 9 \cdot, 9$ & $7 \leq+7,9$ & 0917 & IIVY & 0,19 & $191 \leq, 9$ & 49,11 & Y.1E \\
\hline $1 \wedge r, 1-$ & oror, 9 & $0 \leqslant \mu 4$ & $1 Y \leqslant 0$ & $\Sigma, Y Y$ & $1.17,0$ & $Y \leq \cdot, \wedge V$ & $r .10$ \\
\hline & 19.79 & $1 \cdot v r y$ & YVII & $7,9 V$ & $91 \vee, q$ & 1 M, Vo & $r .17$ \\
\hline$\Lambda \leqslant Y \wedge$ & 51919 & $|r \leq q|$ & YAVE & $V, 07$ & $17+9,9$ & 417,90 & Y.IV \\
\hline 9000 & $Y \leq 0.1$ & $1 \leqslant 904$ & $\mu .11$ & $1, .0$ & YV.O,. & rro,91 & $Y .11$ \\
\hline $7 \leq 90$ & YMO.O & $1 V \cdot 1$. & 111 & $V, \Sigma \Lambda$ & $1 V 9 \cdot, r$ & $r r q, r q$ & $r .19$ \\
\hline$r \leqslant \wedge 9,0$ & $1.0 Y 7,1$ & $V \cdot r V, r$ & IOY,Y & 7,0 & ץঙч৯, & & المتوسط \\
\hline$\wedge \wedge, \bar{T}$ & $79,$. & $7 r, \lambda$ & $0 \wedge, \cdot$ & 10,5 & $\varepsilon \leqslant, 0$ & $r 9,0$ & .V.C \\
\hline
\end{tabular}

المصدر: وزارة الزراعة واستصلاح الأراضي، قطاع الثئون الاقتصادية، الادارة المركزية للاقتصاد الزراعي، نشرة الاحصاءات الزير اعية، أعداد متفرقة.

جدول ع : تقدير معادلات الاتجاه الزمنى للمتغيرات الإتتاجية والاقتصادية لمحصول القطن في مصر خـلال القتـــة (r.19-r...0)

\begin{tabular}{|c|c|c|c|c|c|}
\hline معدل التغير \% & ف & $j$ & المعادلة & الوحدة & البيان \\
\hline $0,0-$ & $* " 9,1$ & $\cdot, \leqslant 1$ & $\begin{array}{r}\text { Ln } Y=6.29-0.055 X \\
(-3.12)^{* *}\end{array}$ & ألف فدان & المساحة \\
\hline $0, Y-$ & $" 0,1$ & $\cdot, r q$ & $\begin{array}{r}\text { Ln } Y=8.12-0.052 X \\
(-2.42)^{*}\end{array}$ & ألف قنطار & الإنتاج \\
\hline 9,1 & $" * \varepsilon \cdot r$ & $\cdot, V \leq$ & $\begin{array}{r}\operatorname{Ln} Y=6.35+0.098 X \\
(6.35)^{* *}\end{array}$ & جنيه/طن & السعر المزرعي \\
\hline $1 \cdot, v$ & $" 00,1 \leq$ & $\cdot, \lambda$. & $\begin{array}{r}\operatorname{Ln} Y=7.79+0.107 X \\
(7.43)^{* *}\end{array}$ & جنيه/فدان & إجمالي التكاليف \\
\hline $1 \cdot, 1$ & "rr,O & TYT, & $\begin{array}{r}\text { Ln } Y=8.22+0.101 X \\
(4.74)^{* *}\end{array}$ & جنيه/فدان & إجمالي عائد \\
\hline $1 r$ & ${ }^{*} \wedge, 7$ & $\cdot, \leqslant 1$ & $\begin{array}{r}\mathrm{Y}=-127+0.453 .6 \mathrm{X} \\
(2.90)^{*}\end{array}$ & جنيه/فدان & صافي عائد الفدان \\
\hline
\end{tabular}

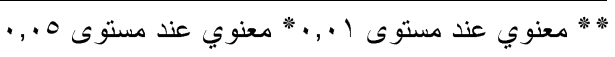

المصدر: حسبث من الجدول (r) (r) 
ثانياً: المؤشرات الإنتاجية والاقتصادية لمحصول القطن بالعينة البحثية بمحافظة البحيرة:

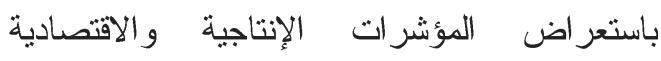
لمحصول القطن بفئات العينة البحثية بمحافظة البحيرة

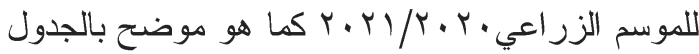
(0) يتبين أن استخدام مستلزمات الإنتاج ممثلة في كمية التقاوي المستخدمة في الزراعة لمحصول القطن قد

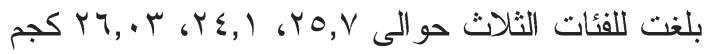
لكل منهم على التزتيب، في حين بلغت كمية الأسمدة البلدية المستخدمة في الزراعة لإنتاج القطن لفئات

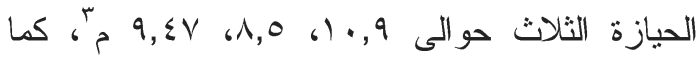

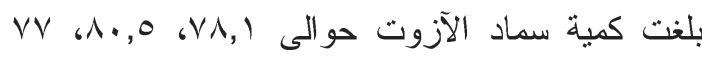
وحدة فعالة، كما بلغت كمية السماد الفوسفات للفئات

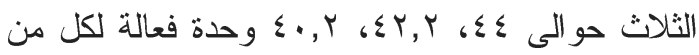
فئات الحيازة الثلاث على الترتيب، بينما بلغت قيمة

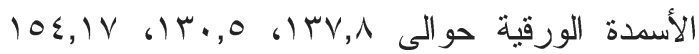
جنيه لكل من الفئات الثناث على التزتيب، في حين

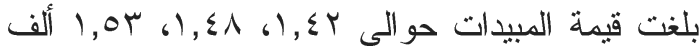
جنيه لكل من الفئات الثلاث على الترتيب. أما ما يتعلق بخدمات عنصر العمل البشري فيلاحظ تتاقص كمية العمل البشري للفدان مع زيادة سعة

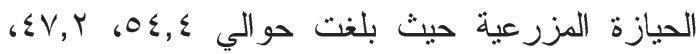

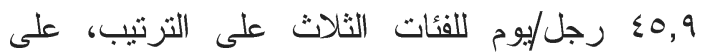
العكس من خدمات العمل الآلي الذي يزداد مع تز ايد

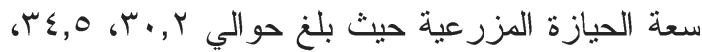

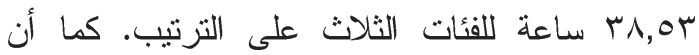
الإنتاجية الفدانية ازدادت بزيادة سعة المزرعة حيث

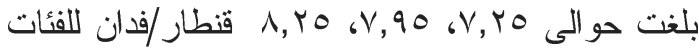
الثلاث على التزتيب، وتنين من خلال تحليل التباين اللفرق بين متوسطات الإنتاجية لفئات العينة البحثية وجود فروق معنوية إحصائياً بينها وفقًا لقيمة إحصائية
كما تز اوح إجمالي التكاليف الفدانية بين حد أدنى بلغ

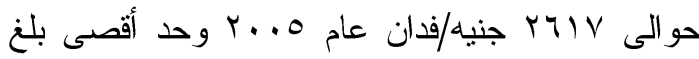

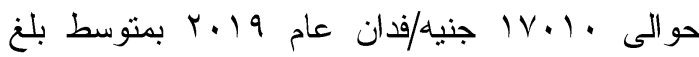

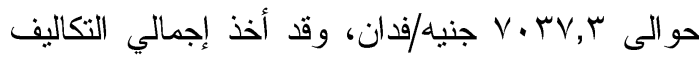

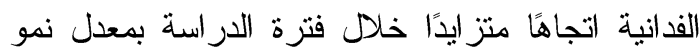

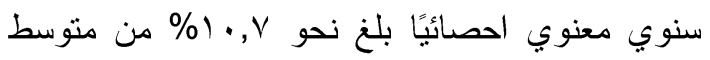

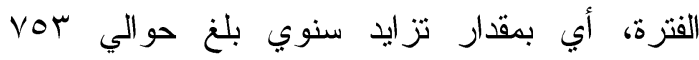
جنيه/فدان. وتراوح إجمالي عائد الفدان لمحصول القطن بين

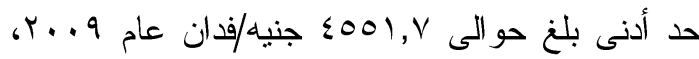

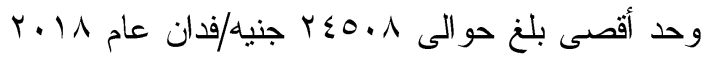

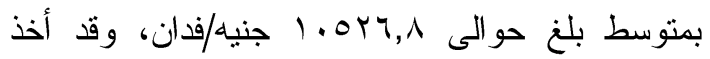

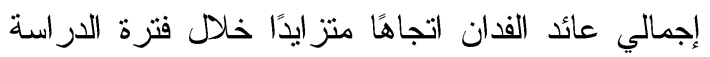

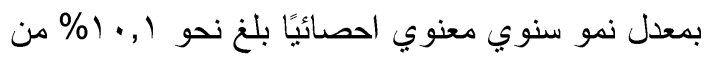

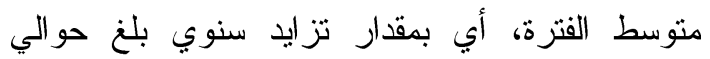

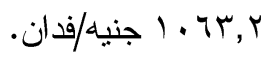
كما تراوح صافي عائد الفدان لمحصول القطن بين حد أدنى متمنل في خسارة قدرها

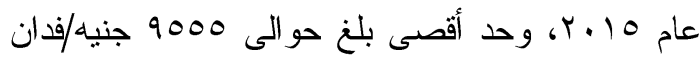

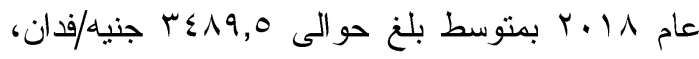
وقد أخذ إجمالي عائد الفدان اتجاهًا متز ايدًا خلال فترة

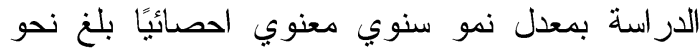

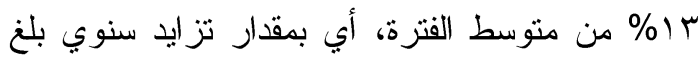

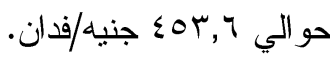
هذا وتشير القيم المرتفعة لمعامل الاختلاف للمؤشرات الإنتاجية والاقتصادية لمحصول القطن إلى زيادة التشتت وانخفاض الثبات لتلك المؤشرات خاصة فيما يتعلق بصافي العائد لفدان محصول القطن الذي بلغ نحو ؟1^,؟\% وهو يدل على ارتفاع درجة المخاطرة

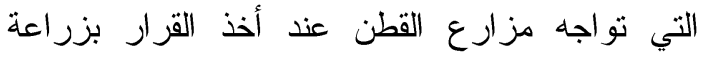
المحصول. 
و

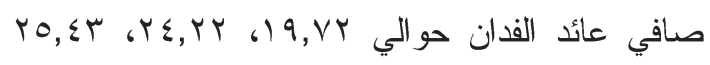
ألف جنيه للفئات الثناث بنفس الترتيب، وبالتالي فإن

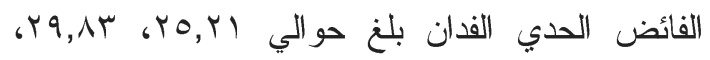

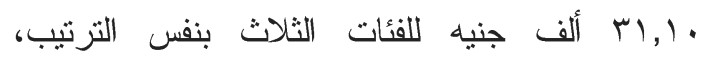
ويلاحظ ارتفاع مؤشرات الربحية مع زيادة سعة المزرعة فبلغ العائد على الجنيه المنفق لفئات الحيازة زئنة

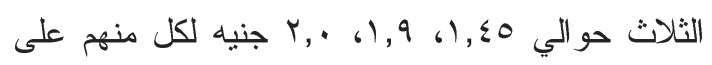
الترتيب الأمر الذي انعكس على زيادة نسبة العائد إلى هـ

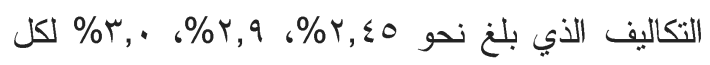
منهم وبنفس الترتيب. الأمر الذي يشير إلى جدوى

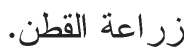

وتتير نتائج مؤشرات الربحية الفدانية فتحقق أعلى سعر مزرعي للفئة الحيازية الثانية بمتوسط بلغ حو الى لى .

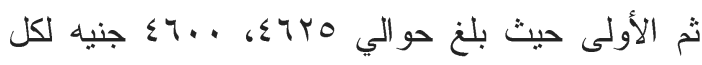
منهما على التو الي. وتعد هذه الأسعار مجزية ومحفزة للمز ارع على زر اعة محصول القطن وتعود هذه الزيادة وندان في المقام الأول إلى ارتفاع السعر العالمي لمحصول

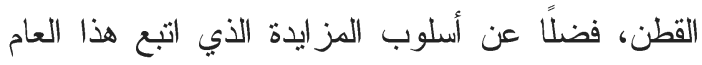
لشراء المحصول من المزارع و الذي ثبت نجاحه في

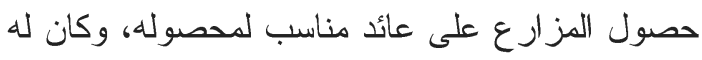

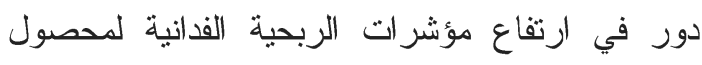

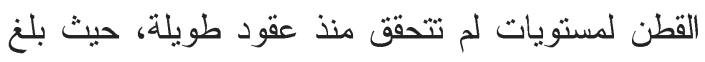

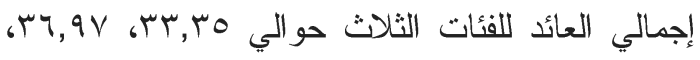

جدول ه: المؤشرات الإنتاجية والاثتصادية الفدانية لمحصول القطن بالعينة البحثية في محافظة البحيـرة للموســـ

\begin{tabular}{|c|c|c|c|c|}
\hline (أكثر من بـ أفندة) & 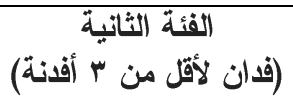 & (أقل من فدان) & الوحدة & البيان \\
\hline Y4, & $r \varepsilon, 1$ & YO,Y & كجم & تقاوي \\
\hline $9, \sum V$ & $\lambda, 0$ & $1 \cdot, 9$ & $\frac{5}{4}$ & سماد بلدي \\
\hline$V V$ & $\lambda \cdot, 0$ & $\vee \wedge, 1$ & وحدة فعالة & سماد آزوت \\
\hline$\varepsilon \cdot, Y$ & $\varepsilon Y, Y$ & $\leqslant \leqslant$ & وحدة فعالة & سماد فوسفات \\
\hline $10 \xi, 1 V$ & $1 \mu \cdot, 0$ & $1 \mu v, \Lambda$ & جنيه & أسمدة ورقبة \\
\hline IOMI,T & $1 \leqslant V V$ & $1 \leqslant 1 \wedge, r$ & جنيه & مبيدات \\
\hline$\leqslant 0,9$ & $\Sigma V, Y$ & $0 \leqslant, \leqslant$ & رجل/يوم & عمل بشري \\
\hline$r \Lambda, O r$ & $r \leqslant, 0$ & $r \cdot, r$ & نساعة & عمل آلي \\
\hline$\Lambda, Y_{0}$ & $V, 90$ & $V, Y_{O}$ & قنطار /فدان & الإنتاجية \\
\hline STYO & $\leqslant 70$. & $\leqslant 7 \ldots$ & جنيه & سعر وحدة الناتج \\
\hline$r 1104$ & r9971 & TrRo. & جنيه & إجمالي العائد \\
\hline$V .09$ & $V I r V, V$ & $\lambda / r 0, V$ & جنيه & تكاليف متغيرة \\
\hline $0747, V$ & 0711 & $0 \leq 9 \wedge, \vee$ & جنيه & تكاليف ثابتة \\
\hline IYVYO,V & IYVO.,V & IM4TE, & جنيه & إجمالي التكاليف \\
\hline$r 0 \leqslant r \cdot r$ & $r \leq r \mid V, r$ & $19 \times 10,7$ & جنيه & صافي العائد \\
\hline$r 1.9 V$ & $r q \wedge r \cdot, r$ & YOYIE,r & جنيه & الفائض الحدي \\
\hline$r, \ldots$ & 1,9 & $1, \leqslant 0$ & جنيه & العائد على الجنيه \\
\hline$r, \ldots$ & $r, q$. & $r, \leqslant 0$ & $\%$ & نسبة العائد للتكاليف \\
\hline \multicolumn{5}{|c|}{ 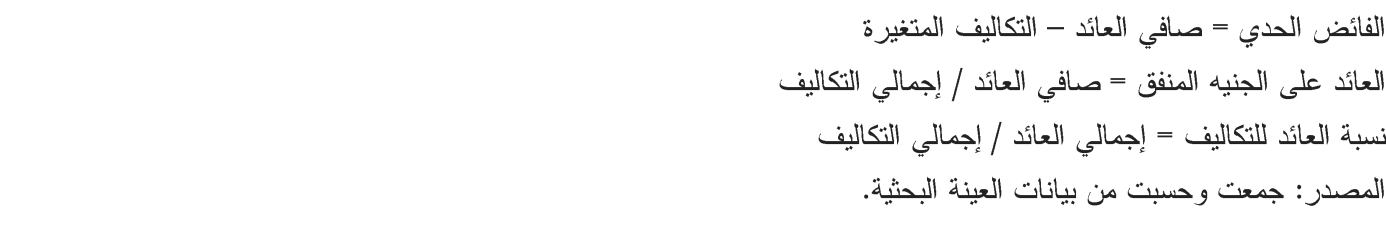 } \\
\hline
\end{tabular}


المزدوجة وثنتت معنويتها الإحصائية عند المستوى

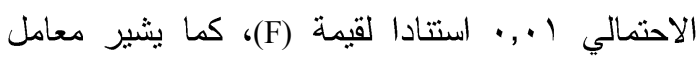

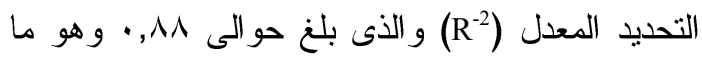

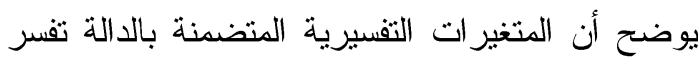

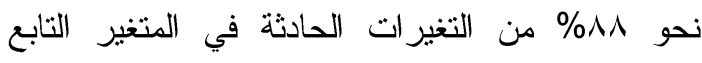
(إنتاجية الفدان)، وأن النسبة المتنقية و البالغة حوالى

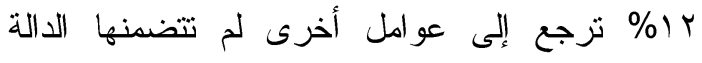
المقدرة. ونتير المعاملات المقدرة إلى المعلى المعنوية الإحصائية لكل من كمية العمل الآلي و (X) كمية التقاوي، وقد بلغ معامل

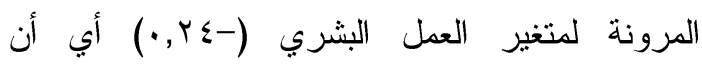
استخدامه يقع في المرحلة الإنتاجية الثالثة غير الرشيدة

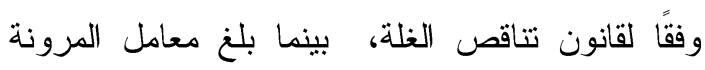

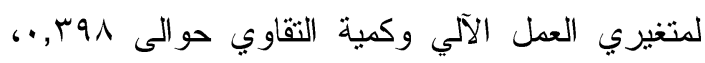
r •ـ, ، ، وهو ما يعني أن زيادة استخدامها أي منها

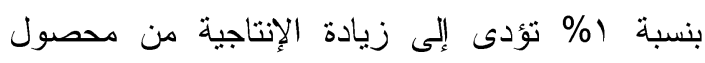

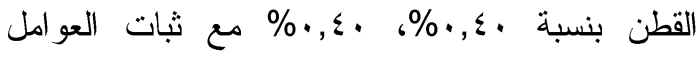

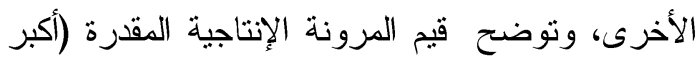

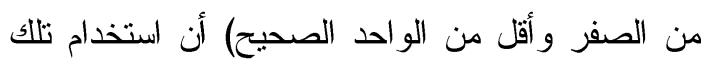
العناصر يقع في المرحلة الإنتاجية الثانية وفقًا قانون

تناقص الغلة.
ثالثًا: التقدير القياسي لاوال إنتاج محصول القطن لعينة

\section{الاراسة في محافظة البحيرة:}

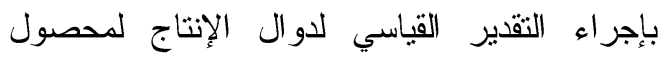
القطن بفئات عينة الدراسة بمحافظة البحبرة لتحديد العوامل المؤثرة في إنتاج المحصول، وتم تحديد تللك

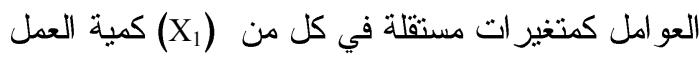

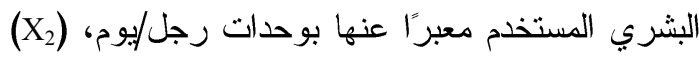
كمية العمل الآلي معبُر ا عنها بعدد ساعات العمل، (X) كمية التقاوي بالكيلو جرام، (X) كمية السماد بالبلدي

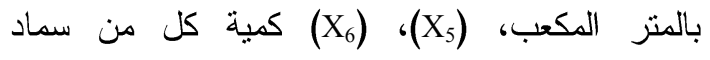

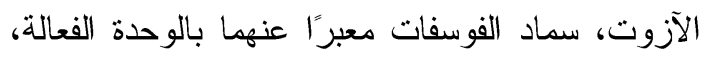
(X)

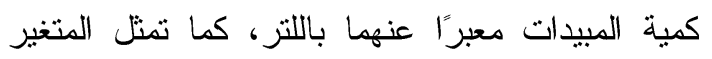

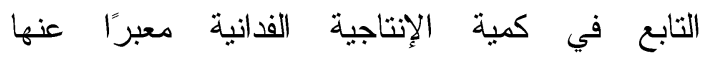
بالقنطار/فدان. وقد تقدير دالة الإنتاج في صورها الرياضية المختلفة باستخدام تحليل الانحدار المتعدد

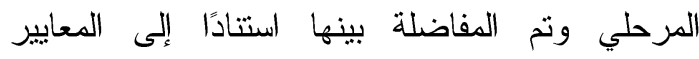
الاحصائية و القياسية و النظرية الاقتصادية وكانت نتائج

التقدير و الموضحة بالجدول (7) كما يلي. (1) دالة إنتاج محصول القطن للفئة الحيازية الأولى: تم تقدير دالة الإتتاج في الصورة اللوغاريتمية جدول Y: التقدير القياسي لاوال إنتاج محصول القطن بعينة الارسة بمحافظة البحيرة للموسم الزراعي

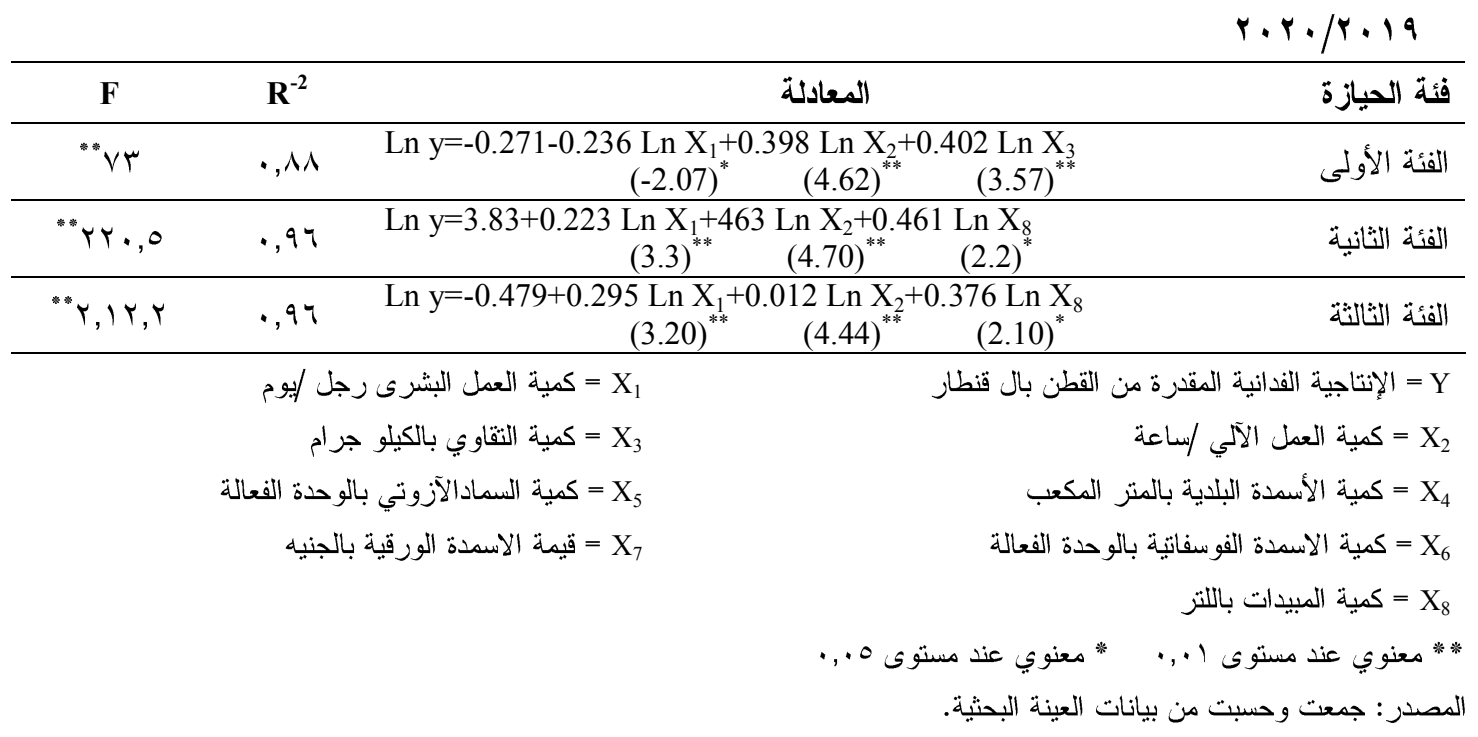


العمل البشرى فقيمة المبيدات حيث بلغت حوالى عـ, •،

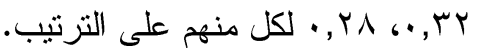

(r) دالة إنتاج محصول القطن للفئة الحيازية الثالثة: تم تقدير دالة الإنتاج في الصورة اللوغاريتمية

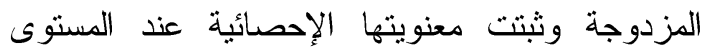
الاحتمالي ل ب,., استتادا لقيمة (F)، كما يشير معامل لإحله

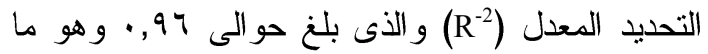
يوضح أن المتغيرات التفسيرية المتضمنة بالدالة تفسر نحو 94\% من التغيرات الحادثة في المتغير التابع (إنتاجية الفدان)، وأن النسبة المنبقية و البالغة حوالى فئل ٪ ترجع إلى عوامل أخرى لم تتضمنها الدالة

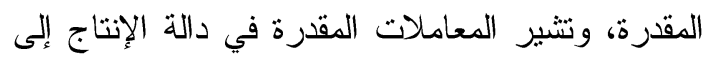

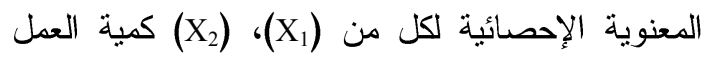

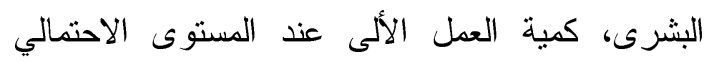

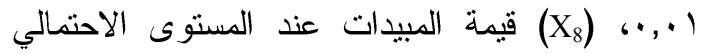

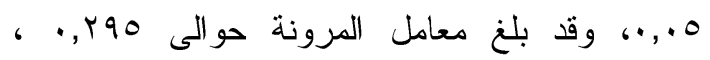

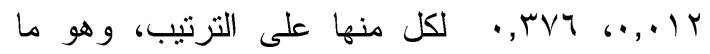

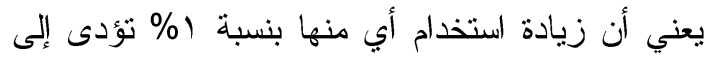

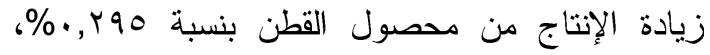

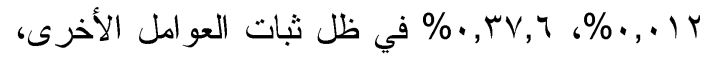
وتوضح قيم المرونة الإنتاجية استخدام تلك العناصر في المرحلة الثانية الاقتصادية، وتعكس المرونة الإجمالية

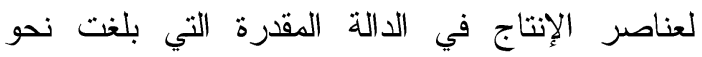
זیT, ، طبيعة العائد المتاقص للسعة. وتنتير القيم

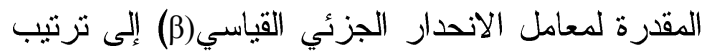
المتغيرات وفقاً لأهميتها في التأثير على المتغير التابع حيث تبين أن كمية العمل الآلي هي الأكثر تأثير، تليها كل من العمل البشرى ، وقيمة المبيدات حيث بلغت

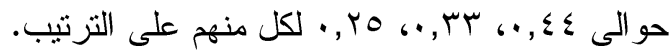

وتعكس المرونة الإجمالية لعناصر الإنتاج في الدالة المقدرة التي بلغت نحو للسعة. وتتير القيم المقدرة لمعامل الانحدار الجزئي لئي

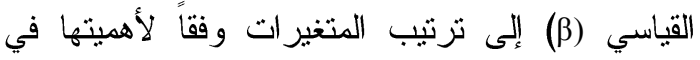
التأثير على المتغير التابع حيث تبين أن كمية السماد

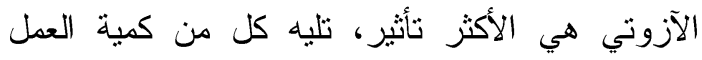

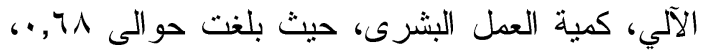

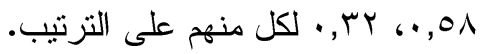
(r) دالة إنتاج محصول القطن للفئة الحيازية الثانية: تم تقدير دالة الإنتاج في الصورة اللوغاريتمية المزدوجة وثنتت معنويتها الإحصائية عند المستوى لإنى

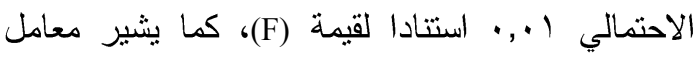

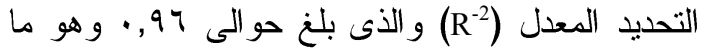
يوضح أن المتغيرات التفسيرية المتضمنة بالدالة تفسر نحو 97\% من التغيرات الحادثة في المتغير التابع (إنتاجية الفدان)، وأن النسبة المتبقية والبالغة حوالى

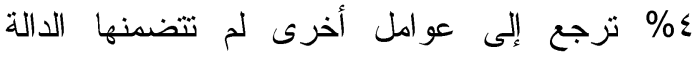

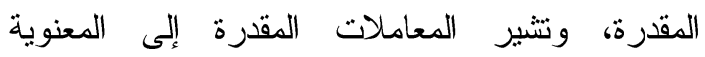
الإحصائية لكل من (X) كمية العمل البشرى، (X)

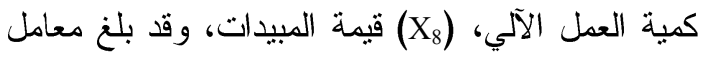

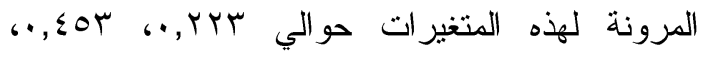
آTگ, • لكل منهم على التزتيب، وهو ما يعني أن زيادة

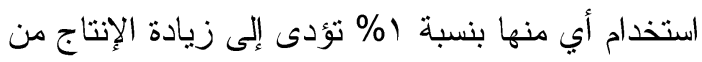

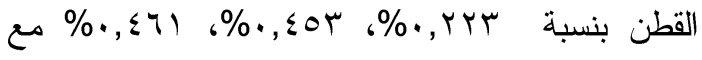
ثبات العوامل الأخرى، وتوضح قيم المرونة الإنتاجية لتلك المتغير ات أن استخدامها يقع في المرحلة الثانية من وند الإنتاج وهى مرحلة الإنتاج الرشيد. وتعكس المرونة

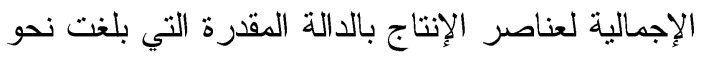
1, I TV المقدرة لمعامل الانحدار الجزئي القياسي (م) إلى ترنيب المتغيرات وفقاً لأهميتها في التأثنير على المتغير التابع حيث تبين أنها على الترتيب كمية العمل الآلي ثم كمية 
العمل الآلي، وكمية التقاوي في إنتاج القطن عن طريق زيادة الكميات المستخدمة من كل منهما حتى تتساوى قيمة الناتج الحدي لكل منهما مع سعر الوحدة لكلاهما.

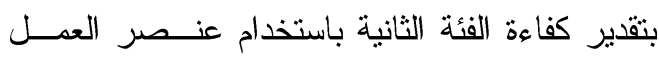

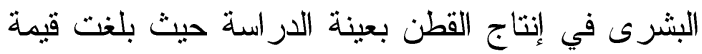

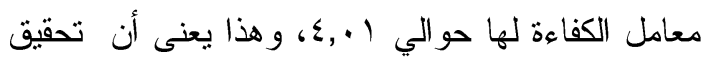

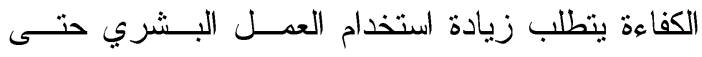

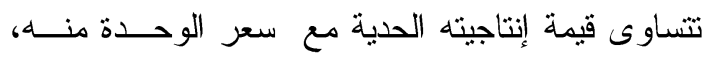

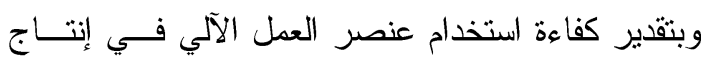

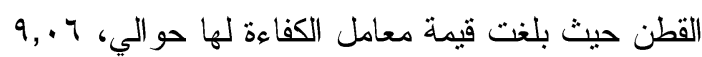

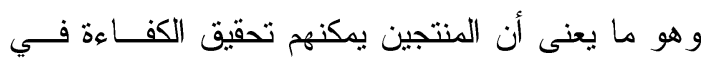

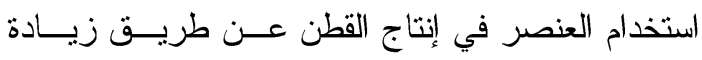
الكمبات المستخدمة منه حتى تتساوى قيمة الناتج الحدي

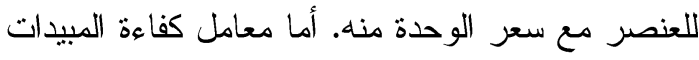

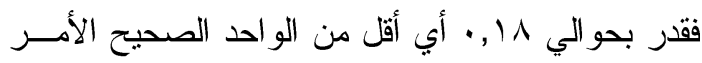

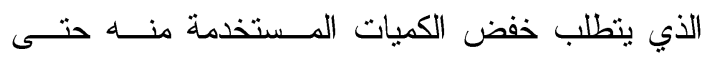

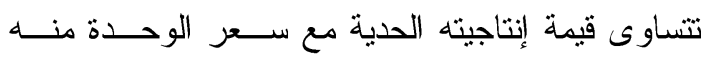
لتحقيق الكفاءة في استخدامه.
(ع) تقدير الكفاءة الاقتصادية لاستخدام عناصر الإتتاج بمزارع إنتاج محصول القطن بالعينة البحثية: تتحقق الكفاءة الاقتصادية لاستخدام العنصر الإنتاجي

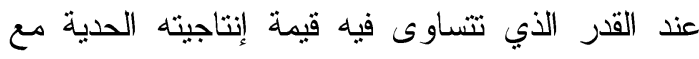
سعر الوحدة من هذا العنصر الإنتاجي، وبقياس الكفاءة الاقتصادية لعناصر الإنتاج المستخدمة في إنتاج محصول القطن بالعينة البحثنة، تنين من النتائج

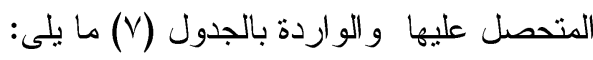
عدم كفاءة استخدام عنصر العمل البشري في الفئة

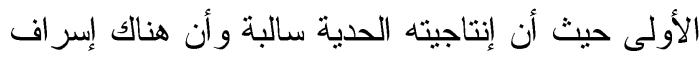
في استخدام العمل البشري واستخدامه يقع في المرحلة الإنتاجية الثالثة غير الرشيدة وأن تحقيق الكفاءة بتطلب تقليل القدر المستخدم من العمل البشري حتى تتساوى قيمة إنتاجيته الحدية مع سعر الوحدة منه (متوسط أجر

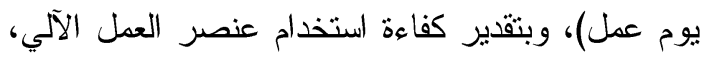
وكمية التقاوي المستخدمة في إنتاج القطن بلغت قيمة

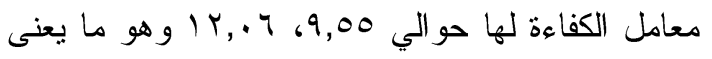
أن المنتجين يمكنهم تحقيق الكفاءة في استخدام عنصر

جدول V: تقدير الكفاءة الاقتصادية لاستخدام عناصر إنتاج محصول القطن وفقاً للالات المقـــرة بمـزارع العينــة

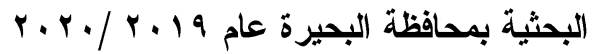

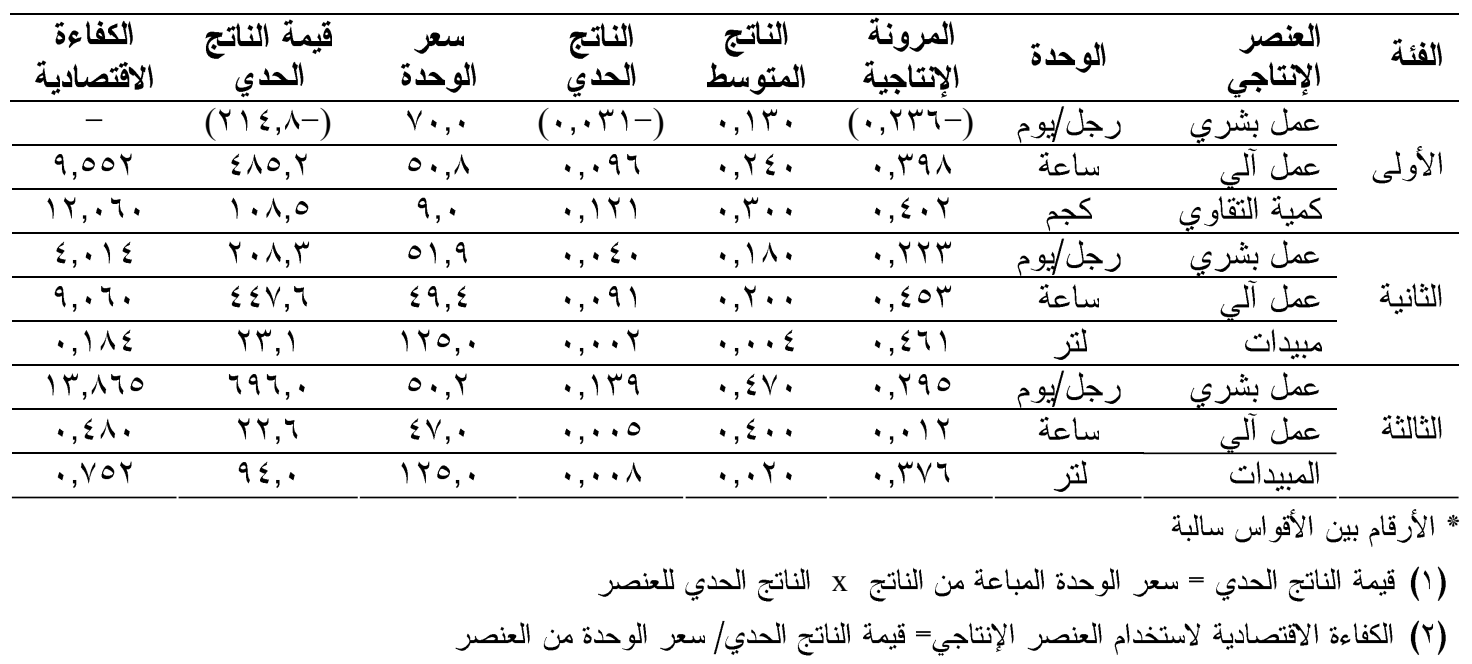
(T) تم حساب متوسط سعر الساعة من العمل الآلي باستخدام المتوسط المرجح بعدد ساعات عمل كل آلة لكل فئة.

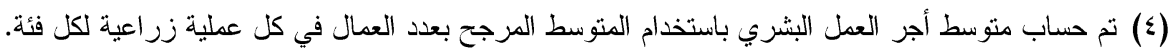

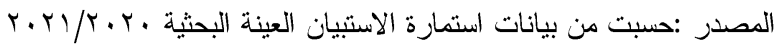


رجل/يوم وذلك لتحقيق نفس المستوى من الإنتاج،

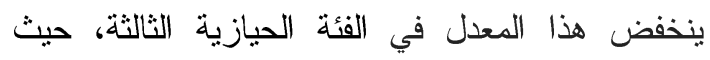

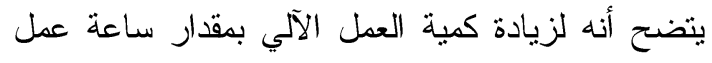

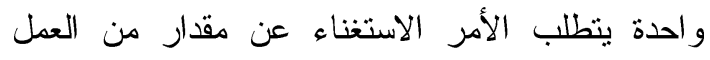

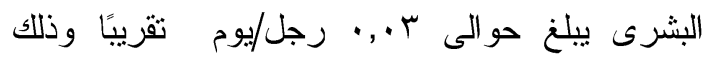

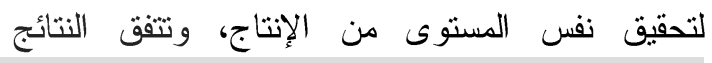

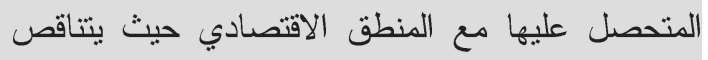

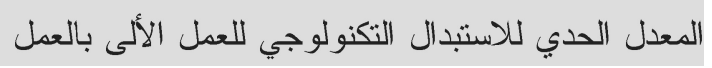
البشرى مع زيادة الكمبات المستخدمة منه. رابعاً: الأهمية النسبية للمشاكل التي تواجه مزارعـي القطن بالعينة البحثية في محافظة البحيرة:

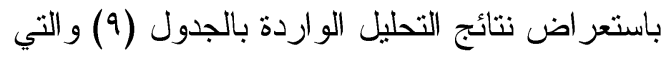

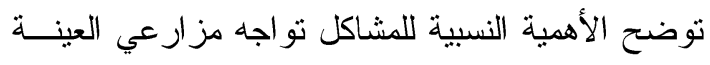

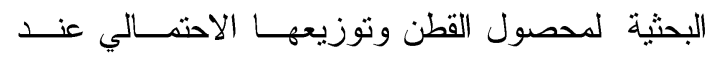

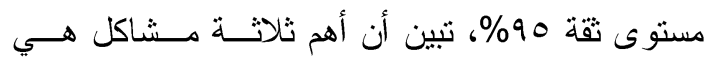

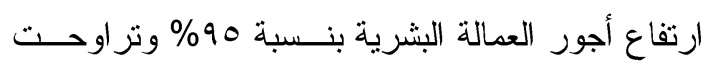

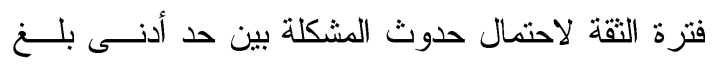

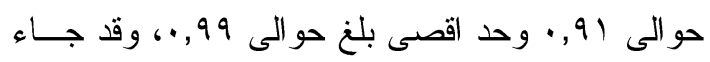

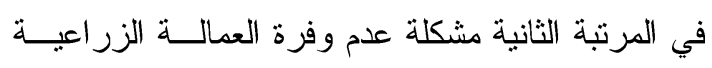

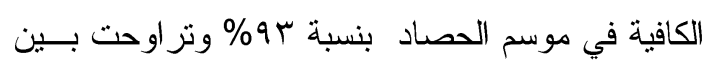

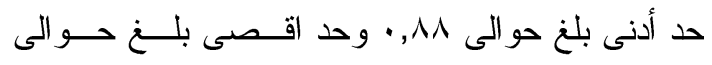

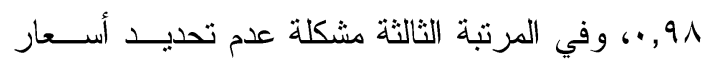

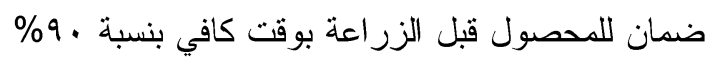

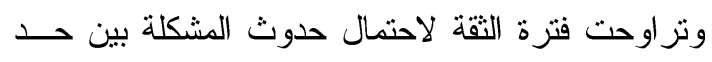

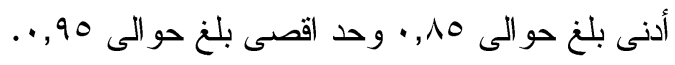

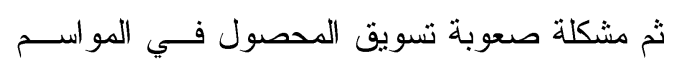

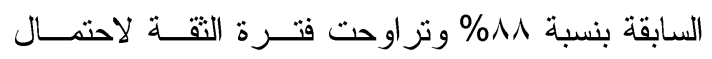

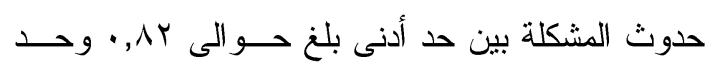

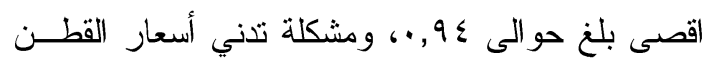

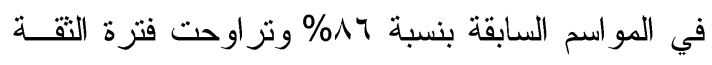

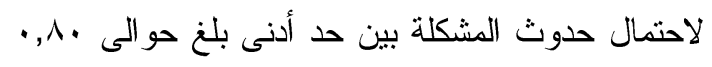

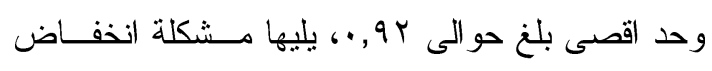

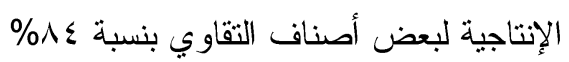

وبتقدير كفاءة استخدام عناصر الإنتاج لفئة الحيازة

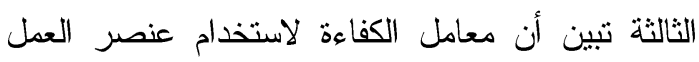

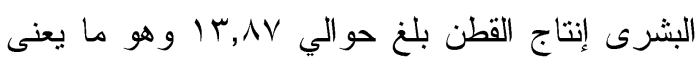
أن المنتجين يمكنهم تحقيق الكفاءة في استخدامه عن بن طريق زيادة الكميات المستخدمة منه حتى نتساوى قيمة نعية

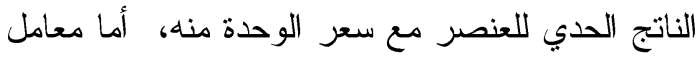
الكفاءة لكل من العمل الآلي والمبيدات فبلغت قيمته هئه

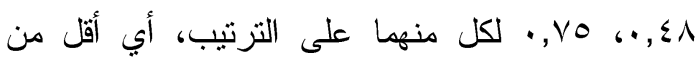
الواحد الصحيح وهو ما يعنى أن المنتجين يمكنهم تحقيق الكفاءة في استخدام العنصرين في إنتاج القطن

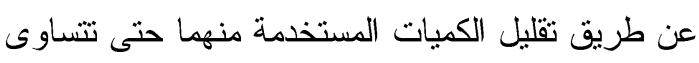
قيمة إنتاجيتهما الحدية مع سعر الوحدة لكل منهما. (0) المعدل الددي للاستببال التكنولوجي للعمل الآلي لئي

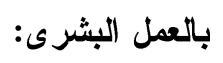

يعد محصول القطن من المحاصيل التي تتطلب

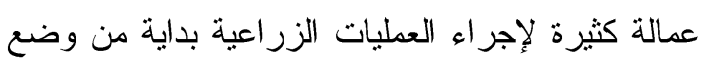

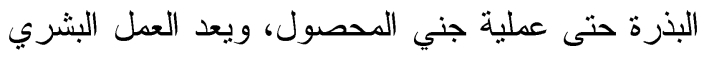

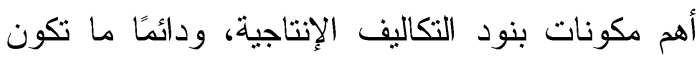
هناك إمكانية للإحلال بين المدخلات الإنتاجية، خاصة لهن ما يتعلق بمدخلات العمل البشري والذي يمكن استبداله بالعمل الآلي ويمكن من خلال دوال الإنتاج المقدرة لمحصول القطن بالعينة البحثية تقدير المعدل الحدي لإي

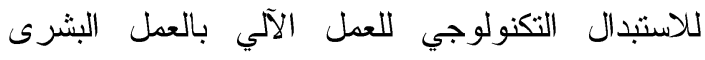
للفئات الحيازية الثلاث كماهو موضح بالجدول(^) يتنين مايلي. بلغ المعدل الحدي للاستبدال التكنولوجي لعنصر العمل الآلي بالعمل البشري في فئة الحيازة الأولى لئل

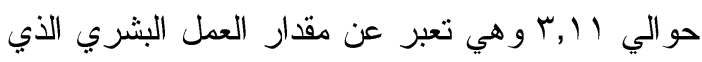
يتطلب الاستغناء عنه لزيادة كمية العمل الآلي بمقدار

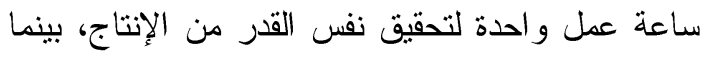

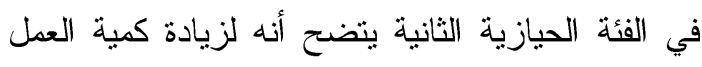
الآلي بمقدار ساعة عمل واحدة يتطلب الأمر الاستغناء

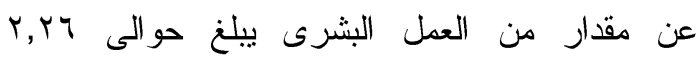


جدول ^: تقدير المعدل الحدي للاستبدال التكنولوجي لعنصر العمل الآلي بالعمل البشرى بالفئات الحيازية لمحصول

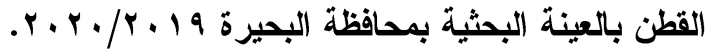

\begin{tabular}{|c|c|c|c|c|c|}
\hline المعدل الحدي & \multicolumn{2}{|c|}{ العمل البشرى(رجل/يوم) } & \multicolumn{2}{|c|}{ العمل الآلى (ساعة) } & \multirow{2}{*}{ فئة الحيازة } \\
\hline للاستبـال التكنولوجي & المتوسط & المرونة & ألمتوسط & المرونة & \\
\hline$r, 11-$ & $\cdot, 1 \pi$ & $\cdot, r \leqslant-$ & $\cdot, r \leq$ & $\cdot, \Sigma$. & الفئة الأولى \\
\hline$r, Y 4$ & $\cdot, 11$ & •, YY & $\cdot, r$. & $\cdot, \leqslant 0$ & الفئة الثانبية \\
\hline$\cdot, \cdot r$ & $\cdot, \leqslant V$ & $\cdot, r \cdot$ & $\cdot, \Sigma$. & $\cdot, ., 1$ & الفئة الثالثة \\
\hline
\end{tabular}

جدول 9: الأهمية النسبية للمشاكل التي تواجه مزارعي القطن بالعينة البحثية بمحافظة البحيرة وتوزيعها الاحتمالي

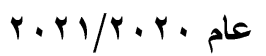

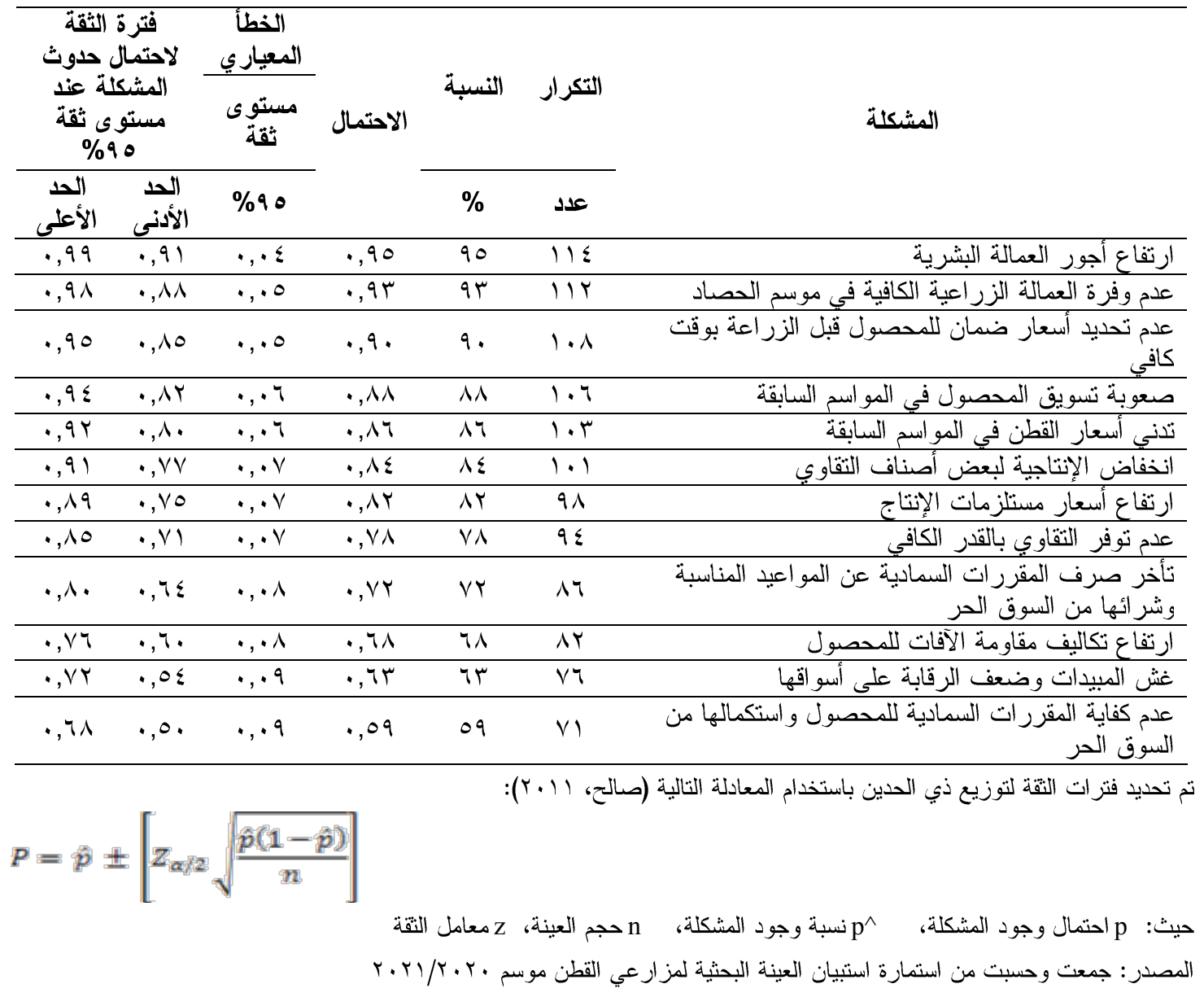

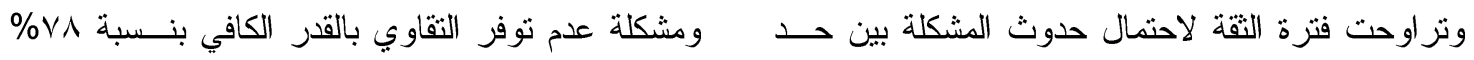

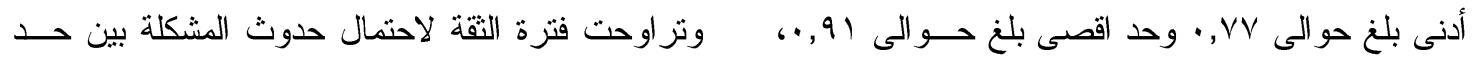

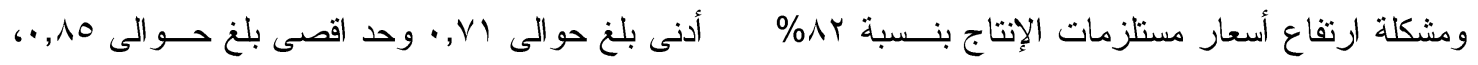

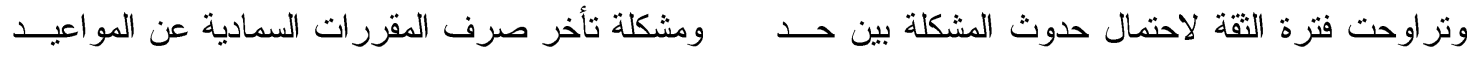

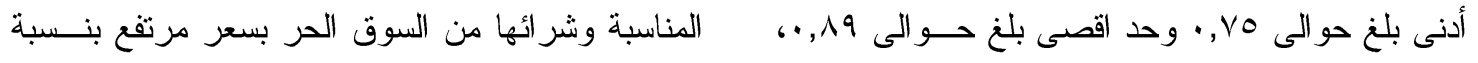


الثاطر، أميرة أحمد محمد (9 + . r)، تحليل اقتصادي للصادرات المصرية من القطن المصري، رسالة دكتور اه، قسم الاقتصاد الزراعي، كلية الزراعة، جامعة القاهرة. جويلي، وائل عبد الفتاح عبد الجيد (11 + (Y)، دراسة اقتصادية لسوق القطن العالمي مع الإشارة بصفة علدة خاصة إلى القطن المصري، رسالة دكتور اه، قسم الإنساة

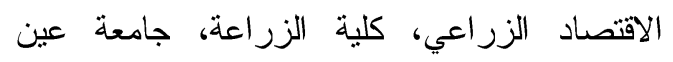
شمس.

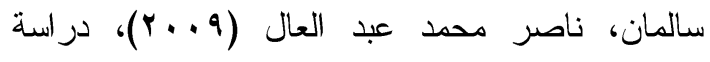
اقتصادية لإنتاج الأقطان المصرية، رسالة دكتور اه،

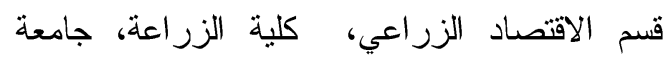

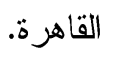

صالح، محمود محمد سليم (11 (1)، مبادئ التحليل الإحصائي، جامعة الإمام محمد بن سعود الإسلامية، الطبعة الأولى.

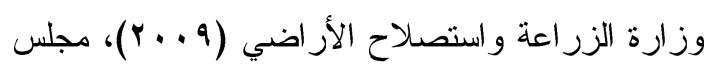

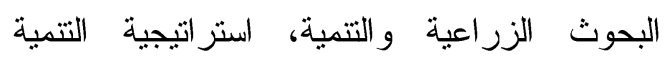

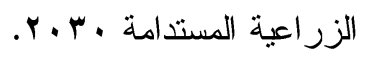

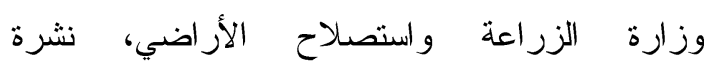
الاحصاءات الزر اعية، أعداد متفرقة.

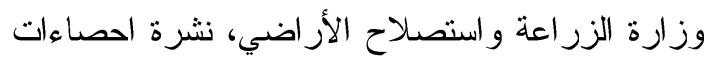

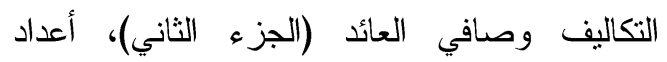
متفرقة.
\% وتز اوحت فترة الثقة لاحتمال حدوث المشكلة بين

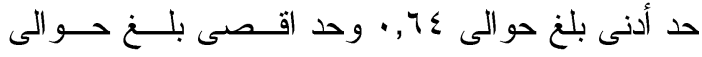
$\cdot, \wedge$. وجاءت في الثلاثة مر اكز الأخيرة مـشكلة ارتفــاع

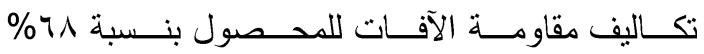

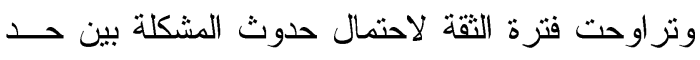

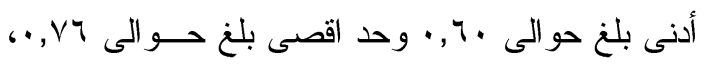
ثم مشكلة غش المبيدات وضعف الرقابة على وحلى أســو اقها

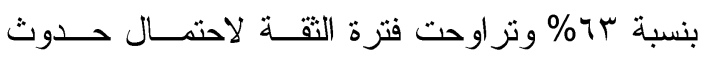

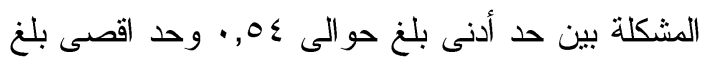

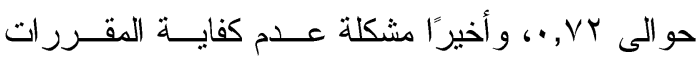
السمادية للمحصول واستكمالها من السوق الحر بنـسبة \% و وتر اوحت فترة التقة لاحتمال حدوث المشكلة بين

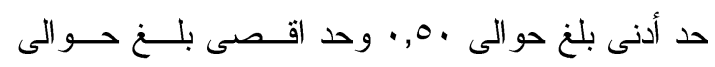
$\cdot ., 71$

\section{المراجع}

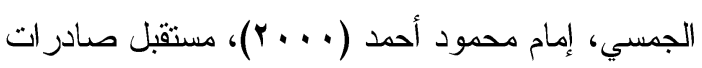

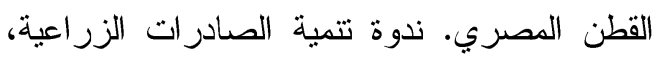

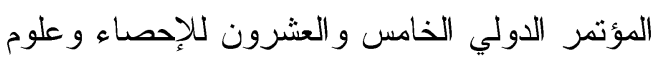

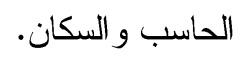




\title{
Economics of Cotton Production in Beheira Governorate
}

\author{
Tarek Morsy Masoud, Shereen Mohamed Effat, Ashraf Elsayed Mostafa \\ Agricultural Economic Research Institute, Agricultural Research Centre.
}

\begin{abstract}
The research aimed to study the economics of cotton production in Egyptian agriculture and Beheira Governorate and to estimate the most important productivity indicators, feddan profitability indicators and the most important determinants of crop production, in addition to identifying the most important problems facing cotton farmers, The results showed that both the area of the cotton crop and the quantity of its production in Egyptian agriculture took a decreasing trend during the study period, while the feddan productivity was characterized by relative stability during the same period. It was also found that the value of the coefficient of variation of the farm price, production costs, and net return per feddan increased during the study period, which is an indication of the high degree of risk facing cotton farmers in Egypt.

From the study of the research sample, it was found that the amount of human labor per feddan decreased with the increase in the capacity of the farm holding, which amounted to about 54.4, 47.2, 45.9 men/day for the three categories, respectively, in contrast to the work of machinery services, which increases with the increase in the capacity of the farm holding, which amounted to about $30.2,34.5,38.53$ hours for the three categories, respectively. The feddan productivity increased by increasing the capacity of the farm, reaching about 7.25, 7.95, 8.25 quintals/feddan for the three categories, respectively, and it was found that there were statistically significant differences between the average productivity of the research sample categories.

It was clear from the estimated production functions that the most important determinants of cotton production are human labor, mechanical work, and agricultural pesticides, and that the farms in the three sample categories do not achieve efficiency in the use of resources, but rather that there is an extravagance in the use of some of them, such as human labor in the first category, to the extent that it achieved negative marginal productivity. The value of the marginal rate of technological substitution of mechanical work with human work decreases with the increase in the amount used in the production process, which is consistent with economic logic.

The most important problems facing cotton farmers in the research sample in Beheira governorate were the problem of high agricultural labor wages, the lack of sufficient labor during the harvest season, the failure to set a guarantee price for the crop in sufficient time before planting, and the problem of the difficulty of marketing production in previous seasons with a relative importance of $95 \%, 93 \%, 90 \%, 88 \%$ of the opinions of farmers in the research sample.

In light of the foregoing results, the study recommends that in order to advance the cotton crop and to complement the success of the marketing system for the 2021 season, it is necessary to reduce marketing risks and protect farmers from price fluctuations by declaring a guarantee price for the crop before planting a sufficient time, as well as switching to machine harvesting of the crop due to the high labor cost and its insufficient availability in the harvest season, especially since there are many countries that preceded us in this field. The pest control of the crop is of great importance, and the control of the market for agricultural pesticides must be tightened and the process of cheating reduced, as well as the provision of agricultural fertilizers to agricultural associations in sufficient and timely manner.
\end{abstract}

